\title{
Article \\ Weight Loss in Post-Chemoradiotherapy Head and Neck Cancer Patients
}

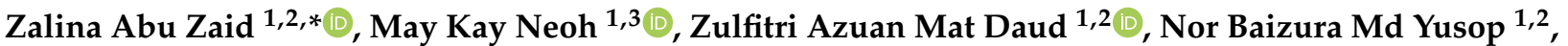 \\ Zuriati Ibrahim ${ }^{1,2}{ }^{D}$, Zuwariah Abdul Rahman ${ }^{3}$, Norshariza Jamhuri ${ }^{1,3}$ and Aishah Zafirah Abdul Azim ${ }^{1,2}$ \\ 1 Department of Dietetics, Faculty of Medicine and Health Sciences, Universiti Putra Malaysia, \\ Serdang 43400, Malaysia; dtneoh@nci.gov.my (M.K.N.); zulfitri@upm.edu.my (Z.A.M.D.); \\ norbaizura@upm.edu.my (N.B.M.Y.); zuriatiib@upm.edu.my (Z.I.); dtshariza@nci.gov.my (N.J.); \\ aishahzaf@upm.edu.my (A.Z.A.A.) \\ 2 Department of Dietetics, Hospital Pengajar Universiti Putra Malaysia, Serdang 43400, Malaysia \\ 3 Department of Dietetic and Food Service, National Cancer Institute, Ministry of Health, 4, Jalan P7, Presint 7, \\ Putrajaya 62250, Malaysia; dtzuwariah@nci.gov.my \\ * Correspondence: zalina@upm.edu.my; Tel.: +60-3-9769-2468
}

check for updates

Citation: Abu Zaid, Z.; Kay Neoh, M.; Mat Daud, Z.A.; Md Yusop, N.B.; Ibrahim, Z.; Abdul Rahman, Z.; Jamhuri, N.; Abdul Azim, A.Z. Weight Loss in Post-

Chemoradiotherapy Head and Neck Cancer Patients. Nutrients 2022, 14 , 548. https://doi.org/10.3390/ nu14030548

Academic Editor: Peter Anderson

Received: 31 December 2021

Accepted: 21 January 2022

Published: 27 January 2022

Publisher's Note: MDPI stays neutral with regard to jurisdictional claims in published maps and institutional affiliations.

Copyright: (C) 2022 by the authors. Licensee MDPI, Basel, Switzerland. This article is an open access article distributed under the terms and conditions of the Creative Commons Attribution (CC BY) license (https:// creativecommons.org/licenses/by/ $4.0 /)$.

\begin{abstract}
Background: Weight loss is well-known among head and neck (HNC) patients during radiotherapy and could continue after the treatment is completed. Weight monitoring is essential for treatment outcomes and cancer surveillance. The purpose of the study is to evaluate the weight loss during and post-treatment among HNC patients. Methods: A total of 45 out of 50 patients post-treatment were included in this secondary treatment. Data were collected at baseline, at the completion of radiotherapy and one month after completion of radiotherapy. Results: The mean weight loss was $4.53 \pm 2.87 \mathrm{~kg}(7.4 \%)$ during treatment and $1.38 \pm 2.65 \mathrm{~kg}(2.1 \%)$ post-treatment. There were significant improvements one month after completion of radiotherapy in Patient-Generated Subjective Global Assessment (PGSGA), muscle mass, nutrition impact symptoms (NIS) score, energy and protein from oral intake $(p<0.0001)$. Energy and protein from oral nutritional supplements (ONS) decreased significantly $(p<0.0001)$. Conclusions: The results of this study underline the importance of early identification and monitoring post-treatment in HNC patients. The post-treatment recovery stage is very important for HNC patients to ensure a healing process.
\end{abstract}

Keywords: oncology; chemotherapy; radiation; weight loss

\section{Introduction}

Head and neck cancer (HNC) include tumors of the oral cavity, oropharynx, hypopharynx, and lymph nodes in the neck [1]. It is the sixth most common form of cancer worldwide, accounting for approximately 5\% of new cancer cases in 2018 [2]. Many HNC patients are diagnosed at an advanced stage (Stage II/IV) and most of them suffer conditions of nutritional vulnerability with a high risk of malnutrition [3]. Tumor location directly impacts patients' oral intake, taste, appetite, and weight loss [4].

Patients with HNC experience substantial weight loss (WL) during and after treatment [5]. More than $50 \%$ of HNC patients lose more than $5 \%$ of their body weight at the time of initial treatment [6]. Critical WL is defined when the body weight loss is $>5 \%$ during RT [7]. Langius et al. (2016) [7] found that patients who had critical WL $>5 \%$ prior to treatment are independently associated with a 1.7 times higher risk of mortality from HNC. In HNC patients at an advanced stage, WL could influence morbidity, which reduces the quality of life and treatment tolerance [8].

Current treatment of advanced HNC requires multimodality therapy such as surgery, radiotherapy (RT), concurrent chemoradiotherapy (CCRT), which have become a standard of care for HNC patients [9]. RT with or without chemotherapy in HNC cancer patients induces oral side effects such as mucositis, dry mouth, and thick saliva mucositis, decreased 
food intake, and WL in up to $80 \%$ of patients [5]. A study by Farhanghar et al. (2014) has shown that patients with multiple nutrition impact symptoms (NIS) or greater total symptom scores are more prone to have reduced dietary intake and WL [10]. Therefore, the total symptom burden is an important risk factor for WL in HNC patients [11].

A study by Ottosson et al. (2013) has shown that HNC patients have a rapid decrease in weight of about $11.3 \%$ during the acute phase, which changed or decreased at the fivemonth follow-up after completion of the RT [5]. Still, there is a lack of studies exploring HNC patients' weight loss and nutritional situation over a longer period, i.e., from diagnosis, during and to the end of the treatment, and post-treatment. This information is essential for nutrition evaluation and for monitoring HNC patients to ensure the healing process is optimized. Hence, this study aimed to investigate changes in body weight and nutritional parameters in HNC patients receiving RT over time.

\section{Materials and Methods}

\subsection{Study Design and Setting}

This study was carried out as part of the previous prospective observational study on the changes in NIS, nutritional and functional status among HNC patients undergoing RT [12].

\subsection{Participants}

Participants in this analysis included 45 out of 50 patients who were recruited one month after completion of their treatment (post-treatment).

\subsection{Data Collection}

Study instrument used was an interview administered questionnaire. Assessment of socio-demographic, clinical characteristics, nutritional status consists of malnutrition status, anthropometric measurements and dietary intake, and nutrition impact symptoms were collected at baseline, end of treatment and one month after completion of RT. Detailed information about the study instruments was reported elsewhere [12].

\subsection{Sample Size}

The required sample size is 40 patients. Detailed information about the sample size calculation was reported elsewhere [12]

\subsection{Ethical Approval}

This study has obtained ethical approval, as described in detail elsewhere [12].

\subsection{Statistical Analysis}

For the statistical analysis, the IBM SPSS Statistics for Windows, Version 23.0. Armonk, NY: IBM Corp. was used. Shapiro-Wilk test was used to check for normality of the data. If the data were not normally distributed, the natural logarithm of the values was used. Continuous variables which are normally distributed are presented as mean and standard deviation while median and interquartile range is presented for continuous variables which are not normally distributed. The Mann-Whitney U-test was used to test the differences between groups for ordinal data. Changes of normally distributed continuous variables over time (body weight, muscle mass, total energy and protein intake) were used repeated-measures ANOVA. A Friedman test was used to analyze changes of abnormally distributed continuous variables (PGSGA score, fat mass, NIS score, and, ONS energy and protein intake). In the case of deviation from sphericity, a GreenhouseGeisser correction for degrees of freedom was used. A statistical probability of $p<0.05$ was considered significant. 


\section{Results}

Table 1 described the socio-demographic characteristics, clinical characteristics, lifestyle habits and type of treatment of the HNC patients. The median age in the population was 60 years old and the age range was 21 to 78 years old. More than half (52\%) of the patients were in the old adults' category at $\geq 60$ years old. The recruitment for this study has shown that there are more males than females with HNC (78\% versus $22 \%)$. Twenty-one Malay $(42 \%)$, nineteen Chinese (38\%) and ten Indian (20\%) patients participated in this study. There were $40 \%$ that had a lower education level, $68 \%$ were married, $28 \%$ were working. Half of the 50 patients were active smokers or ex-smokers. The majority of the patients were non-alcoholic with $76.5 \%$. A total of $28 \%$ of them had a family history of cancer and $58 \%$ had pre-existing comorbidities. In this study, $84 \%$ were in stage III and IV, and over half of the HNC patients had nasopharynx cancer. In addition, seventeen patients received RT (34\%) and thirty-three patients received CCRT (60\%).

Table 1. Patient socio-demographics, clinical characteristics, lifestyle habits and types of treatment.

\begin{tabular}{|c|c|}
\hline Characteristics & Overall $(n=50)$ \\
\hline Age (years), median (IQR) & $60(49-67)$ \\
\hline \multicolumn{2}{|l|}{ Age groups, $n(\%)$} \\
\hline$<40$ years old & $6(12)$ \\
\hline $40-59$ years old & $18(36)$ \\
\hline$\geq 60$ years old & $26(52)$ \\
\hline \multicolumn{2}{|l|}{ Gender, $n(\%)$} \\
\hline Male & $39(78)$ \\
\hline Female & $11(22)$ \\
\hline \multicolumn{2}{|l|}{ Race, $n(\%)$} \\
\hline Malay & $21(42)$ \\
\hline Chinese & $19(38)$ \\
\hline India & $10(20)$ \\
\hline \multicolumn{2}{|l|}{ Education level, $n(\%)$} \\
\hline Primary or below & $20(40)$ \\
\hline Secondary or above & $30(60)$ \\
\hline \multicolumn{2}{|l|}{ Marital status, $n(\%)$} \\
\hline Single & $13(26)$ \\
\hline Married & $37(74)$ \\
\hline \multicolumn{2}{|l|}{ Working status, $n(\%)$} \\
\hline Yes & $14(28)$ \\
\hline No & $36(72)$ \\
\hline \multicolumn{2}{|l|}{ Co-morbidities, $n(\%)$} \\
\hline Yes & $29(58)$ \\
\hline No & $21(42)$ \\
\hline \multicolumn{2}{|l|}{ Smoking history, $n$ (\%) } \\
\hline Active smoker & $7(14)$ \\
\hline Non smoker & $25(50)$ \\
\hline Ex-smoker & $18(36)$ \\
\hline \multicolumn{2}{|l|}{ Alcohol history, $n(\%)$} \\
\hline Yes & $12(24)$ \\
\hline No & $38(76)$ \\
\hline \multicolumn{2}{|l|}{ Family history, $n(\%)$} \\
\hline Yes & $14(28)$ \\
\hline No & $36(72)$ \\
\hline \multicolumn{2}{|l|}{ Tumor location, $n(\%)$} \\
\hline Tongue & $7(14)$ \\
\hline Mouth & $6(12)$ \\
\hline Salivary gland & $3(6)$ \\
\hline Tonsil & $2(4)$ \\
\hline Oropharynx & $2(2)$ \\
\hline Nasopharynx & $26(52)$ \\
\hline Sinuses & $1(2)$ \\
\hline Larynx & $3(6)$ \\
\hline \multicolumn{2}{|l|}{ Stage of tumor, $n(\%)$} \\
\hline $1-2$ & $8(6)$ \\
\hline \multirow{2}{*}{\multicolumn{2}{|c|}{ Type of treatment, $n(\%)$}} \\
\hline & \\
\hline Radiotherapy & $17(34)$ \\
\hline Chemoradiotherapy & $33(66)$ \\
\hline
\end{tabular}


In this study, $50 \mathrm{HNC}$ patients were able to complete RT treatment (7 weeks) and completed the data collection until the end of treatment. However, there were five HNC patients that defaulted on the follow-up after 1 month of treatment. Finally, the total number of HNC patients eligible for post-treatment analysis was $45 \mathrm{HNC}$ patients.

Table 2 shows the changes in nutritional status and NIS at baseline, end and posttreatment. The mean weight loss was $4.53 \pm 2.87 \mathrm{~kg}(7.4 \pm 4.1 \%)$ during treatment and the median weight loss was $0.7 \mathrm{~kg}$ and a range of -3.9 to $0.6 \mathrm{~kg}(2.1 \pm 4.7 \%)$ post-treatment. The body weight was $60.24 \pm 14.73 \mathrm{~kg}$ at baseline of treatment and significantly declined to $55.71 \pm 13.62 \mathrm{~kg}$ at the end of treatment with a further drop to $56.26 \pm 1.8 \mathrm{~kg}$ at posttreatment $(p<0.0001)$. Fat mass loss was higher compared to muscle mass loss for both during and post-treatment. The PGSGA score showed a significant increase from baseline to end of treatment but was able to improve by post-treatment $(p<0.0001)$. The mean NIS score significantly increased from $21.78 \pm 4.59$ to $48.34 \pm 8.79$ at the end of treatment but improved to $27.08 \pm 10.19$ by post-treatment $(p<0.0001)$.

The total energy and total protein intake increased from baseline until post-treatment but there were no significant changes for both results. Nevertheless, there were significant changes in oral food energy, oral food protein, ONS energy and ONS protein intakes. The oral food energy and protein intakes declined from baseline to end of treatment but improved again at post-treatment, while the ONS energy and protein intakes increased from baseline to end of treatment but dropped back at post-treatment $(p<0.0001)$.

The percentage of diet-type changes in head and neck cancer patients at baseline, end and post-treatment is presented in Figure 1. The majority of the patients were on a normal $\operatorname{diet}(72 \%)$ at baseline and decreased to $2 \%$ by the end of treatment but increased back to $42 \%$ at post-treatment. A soft diet was gradually increased from $10 \%$ to $38 \%$ by the end of treatment but dropped back to $22 \%$ at post-treatment. At the same time, there was an increasing trend for a blended diet, full liquid diet and clear liquid diet at the end of the treatment. A total of $12 \%$ of HNC patients on Ryle's tube feeding at the end of treatment remain here at post-treatment. HNC patients who were on liquid textures (blended diet, full liquid diet, clear liquid, Ryle's tube feeding) was at 58\% at end of treatment and $68 \%$ at post-treatment while HNC patients who were on a solid or semi-solid diet (normal diet, soft diet, minced diet) was $42 \%$ at the end of treatment and $32 \%$ at post-treatment.

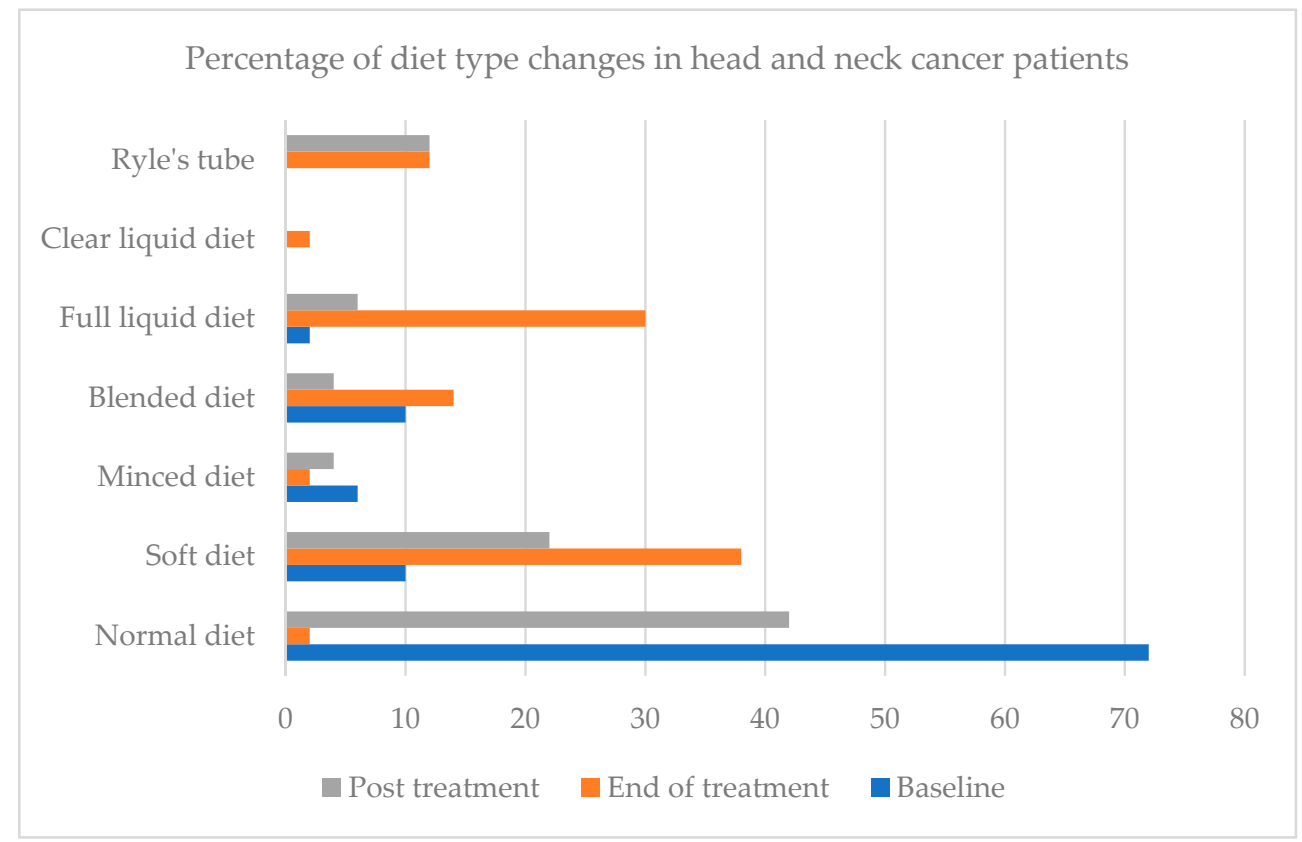

Figure 1. Changes of diet type at baseline, end and post-treatment of head and neck cancer patients. 
Table 2. Changes in nutritional status and NIS at baseline, end and post-treatment.

\begin{tabular}{|c|c|c|c|c|c|}
\hline Variables & Baseline $(n=50)$ & End of RT $(n=50)$ & Post-RT $(n=45)$ & $\mathrm{X}^{2}$ & $p$-Value \\
\hline Body weight $(\mathrm{kg})^{+}$ & $60.24 \pm 14.73$ & $57.64 \pm 12.97$ & $56.26 \pm 12.24$ & 20.668 & $<0.0001$ * \\
\hline PGSGA score $\mathbb{I}$ & $8.72 \pm 6.86$ & $25.82 \pm 5.34$ & $13.11 \pm 7.87$ & 58.47 & $<0.0001$ * \\
\hline Muscle mass $(\mathrm{kg})^{+}$ & $43.03 \pm 8.12$ & $41.30 \pm 8.13$ & $42.31 \pm 1.08$ & 0.708 & $<0.0001 *$ \\
\hline Fat mass $(\mathrm{kg})^{\mathbb{I I}}$ & $15.23 \pm 9.17$ & $12.67 \pm 8.3$ & $11.58 \pm 8.29$ & 61.1 & $<0.0001$ * \\
\hline NIS score II & $21.78 \pm 4.59$ & $48.34 \pm 8.79$ & $27.08 \pm 10.19$ & 67.32 & $<0.0001$ * \\
\hline $\begin{array}{l}\text { Total Energy Intake } \\
\text { (Kcal/day) }^{\dagger}\end{array}$ & $1412 \pm 589$ & $1554 \pm 482$ & $1598 \pm 563$ & 0.771 & 0.512 \\
\hline $\begin{array}{l}\text { Total protein Intake } \\
\qquad(\mathrm{g} / \text { day })^{+}\end{array}$ & $63 \pm 60$ & $66 \pm 21$ & $80.8 \pm 48.03$ & 13.1 & 0.067 \\
\hline Total energy & & & & & \\
\hline $\begin{array}{l}\text { intake/current weight } \\
\qquad(\mathrm{kcal} / \mathrm{kg} \mathrm{BW})^{+}\end{array}$ & $23.60 \pm 8.58$ & $26.26 \pm 9.33$ & $27 \pm 1.7$ & 0.965 & 0.402 \\
\hline Total protein & & & & & \\
\hline $\begin{array}{l}\text { intake/current weight } \\
(\mathrm{g} / \mathrm{kg} / \mathrm{BW})^{+}\end{array}$ & $1.03 \pm 0.43$ & $1.11 \pm 0.36$ & $1.27 \pm 0.80$ & 1.723 & $0.049 *$ \\
\hline $\begin{array}{l}\text { Oral food Energy Intake } \\
{\text { (Kcal/kg/day })^{+}}^{\text {(Kcal }}\end{array}$ & $1355 \pm 62$ & $413 \pm 426$ & $811 \pm 548$ & 10.709 & $<0.0001$ * \\
\hline 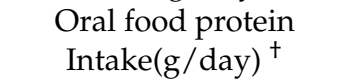 & $60 \pm 31$ & $16 \pm 21$ & $41.4 \pm 30.2$ & 5.881 & $<0.0001$ * \\
\hline $\begin{array}{l}\text { ONS Energy Intake } \\
\text { (Kcal/day) II }\end{array}$ & $56 \pm 181$ & $1141 \pm 572$ & $1086 \pm 569$ & 72.473 & $<0.0001$ * \\
\hline $\begin{array}{l}\text { ONS Protein Intake } \\
\text { (g/day) } \mathbb{I}\end{array}$ & $2 \pm 8$ & $50 \pm 24$ & $48 \pm 24$ & 71.605 & $<0.0001$ * \\
\hline
\end{tabular}

Mean, standard deviation (SD); * Significant $(p<0.05)^{\dagger}$ Analyzed by General Linear Model repeated measures. A Greenhouse-Geisser correction for degrees of freedom was used because of deviation from sphericity; $\mathbb{I I}_{\text {I }}$ Analyzed by the Friedman test; a Wilcoxon signed-rank-sum test (baseline vs. end of RT). Abbreviations: PG-SGA: patientgenerated subjective global assessment, BMI: body mass index, NIS: nutrition impact symptoms, ONS: oral nutrition supplements.

At the beginning of treatment, the majority of $\mathrm{HNC}$ patients $(90 \%)$ did not receive any oral nutritional supplement (ONS). However, $96 \%$ of HNC patients were on ONS at end of treatment and $80 \%$ of HNC patients at post-treatment (Table 3 ).

Table 3. Prevalence of ONS use of HNC.

\begin{tabular}{cccc}
\hline $\begin{array}{c}\text { ONS Use } \\
\boldsymbol{n} \mathbf{( \% )}\end{array}$ & $\begin{array}{c}\text { Baseline } \\
(\boldsymbol{n}=\mathbf{5 0 )}\end{array}$ & $\begin{array}{c}\text { End of Treatment } \\
(\boldsymbol{n}=\mathbf{5 0 )}\end{array}$ & $\begin{array}{c}\text { Post-Treatment } \\
(\boldsymbol{n}=\mathbf{4 5})\end{array}$ \\
\hline Yes & $5(10)$ & $48(96)$ & $40(80)$ \\
No & $45(90)$ & $2(4)$ & $5(10)$ \\
\hline
\end{tabular}

Abbreviations: ONS: oral nutrition supplements.

Over half of the patients with HNC had difficulty chewing symptoms and $38 \%$ of them had a loss of appetite and dry mouth symptoms before treatment (Table 4). At the end of treatment, all $50 \mathrm{HNC}$ patients experienced dry mouth and taste changes and more than $80 \%$ of them experienced sore mouth, lack of energy, loss of appetite, difficulty swallowing and chewing (Table 4). While post-treatment, all of the HNC patients had improved NIS.

As presented in Table 5, HNC patients had the highest NIS interference score of taste changes and loss of appetite, followed by swallowing and chewing difficulty, dry mouth, pain, sore mouth and thick saliva at the end of treatment. More than half of HNC patients still experienced taste changes, difficulty chewing, loss of appetite, dry mouth and thick saliva at post-treatment but had improving NIS interference scores. 
Table 4. NIS experiences in HNC.

\begin{tabular}{cccc}
\hline $\begin{array}{c}\text { Nutrition Impact } \\
\text { Symptoms } \boldsymbol{n} \mathbf{( \% )}\end{array}$ & $\begin{array}{c}\text { Baseline } \\
(\boldsymbol{n}=\mathbf{5 0 )}\end{array}$ & $\begin{array}{c}\text { End of Treatment } \\
(\boldsymbol{n}=\mathbf{5 0 )}\end{array}$ & $\begin{array}{c}\text { Post-Treatment } \\
(\boldsymbol{n}=\mathbf{4 5})\end{array}$ \\
\hline Taste changes & $5(10)$ & $50(100)$ & $38(76)$ \\
Difficulty swallowing & $9(18)$ & $47(94)$ & $24(48)$ \\
Difficulty chewing & $26(52)$ & $47(94)$ & $32(64)$ \\
Constipation & $8(16)$ & $29(58)$ & $11(22)$ \\
Loss of appetite & $19(38)$ & $47(94)$ & $27(54)$ \\
Dry mouth & $19(38)$ & $50(100)$ & $36(72)$ \\
Pain & $11(22)$ & $45(90)$ & $22(44)$ \\
Anxious & $9(18)$ & $22(44)$ & $8(16)$ \\
Nausea & $4(8)$ & $22(44)$ & $6(12)$ \\
Lack of Energy & $14(28)$ & $46(92)$ & $22(44)$ \\
Sore mouth & $6(12)$ & $43(86)$ & $12(24)$ \\
Diarrhea & $0(0)$ & $4(8)$ & $1(2)$ \\
Thick saliva & $12(24)$ & $48(96)$ & $8(58)$ \\
Depressed & $2(4)$ & $10(20)$ & $9(16)$ \\
Fullness & $4(8)$ & $26(52)$ & $4(8)$ \\
Vomiting & $3(6)$ & $11(22)$ & $9(18)$ \\
Smell bothersome & $6(12)$ & $36(72)$ & \\
\hline
\end{tabular}

Table 5. Nutrition Impact Symptoms (NIS) interference scores from the Head and Neck Symptoms Checklist (HNSCO) of the patients $(n=50)$ at baseline, end and post-treatment.

\begin{tabular}{cccc}
\hline $\begin{array}{c}\text { NIS Interference } \\
\text { Score (1-5) }\end{array}$ & $\begin{array}{c}\text { Baseline } \\
(\boldsymbol{n}=50)\end{array}$ & $\begin{array}{c}\text { End of Treatment } \\
(\boldsymbol{n}=\mathbf{5 0 )}\end{array}$ & $\begin{array}{c}\text { Post-Treatment } \\
(\boldsymbol{n}=\mathbf{4 5})\end{array}$ \\
\hline Median (IQR) & & & \\
Taste changes & $1(1-1)$ & $5(4-5)$ & $2(2-3)$ \\
Difficulty swallowing & $1(1-1)$ & $4(3-5)$ & $2(1-2.5)$ \\
Difficulty chewing & $2(1-3.25)$ & $4(3-5)$ & $2(1-3)$ \\
Constipation & $1(1-1)$ & $2(1-3)$ & $1(1-1.25)$ \\
Loss of appetite & $1(1-2)$ & $5(4-5)$ & $2(1-3)$ \\
Dry mouth & $1(1-2)$ & $4(3-5)$ & $2(2-3)$ \\
Pain & $1(1-1)$ & $4(3-4.25)$ & $1(1-2)$ \\
Anxious & $1(1-1)$ & $1(1-3)$ & $1(1-1)$ \\
Nausea & $1(1-1)$ & $1(1-3)$ & $1(1-3)$ \\
Lack of Energy & $1(1-2)$ & $3(2.75-4)$ & $1(1-2)$ \\
Sore mouth & $1(1-1)$ & $4(2-5)$ & $2(1-1)$ \\
Diarrhea & $1(1-1)$ & $1(1-1)$ & $1(1-1)$ \\
Thick saliva & $1(1-1.25)$ & $4(3-4)$ & $1(1-1)$ \\
Depressed & $1(1-1)$ & $1(1-1)$ & $1(1-1)$ \\
Fullness & $1(1-1)$ & $2(1-3)$ & $1(1-1)$ \\
Vomiting & $1(1-1)$ & $1(1-1)$ & $3(1-4)$ \\
Smell bothersome & $1(1-1)$ & &
\end{tabular}

Note: Prevalence NIS when severity scores $\geq 2$. Mann-Whitney U test.

\section{Discussion}

The patients in this study started to lose weight significantly during treatment and had further declined body weight until post-treatment (Table 2). With the pre-treatment weight or weight on the first week of radiotherapy as a baseline, the mean percentage of weight loss was already considerable after 2 to 3 weeks of radiotherapy and the weight loss at the end of radiotherapy was even worse. After treatment, weight was monitored and documented and approximately a quarter of the patients had regained weight. It could have been expected that during this period, which might be called rehabilitation, patients should have regained the lost weight. Percentage of weight loss is considered an easy, clinically relevant, simple, and reliable predictor for malnutrition. Involuntary $5 \%$ weight loss in less than 1 month without stabilization or beginning weight gain was shown to be a valid marker for malnutrition in HNC patients. Langius et al. (2016) [7] found that patients 
who experience weight loss of $>5 \%$ within 8 weeks of RT was significant, and was a sign of compromised nutritional status. This was shown to increase the rate of complications, which can lead to high mortality rates and reduce the quality of life.

All the HNC patients were malnourished with $32 \%$ being moderately malnourished and $68 \%$ being severely malnourished at the end of treatment. This is comparable with Wei's study that showed a strong correlation between involuntary weight loss and PG-SGA, where a PG-SGA score difference had a strong positive relationship with the percentage of weight loss at the end of treatment [13]. Malnutrition at the time of diagnosis can negatively affect clinical decisions of treatment options for patients due to unpredictable complications and curative rates in the management of cancer. In addition, it can cause treatment interruption that affects the effectiveness of treatment, high infections risk, delay wound healing, increase the length of hospital stay and increase morbidity and mortality [14]. After a month of treatment, $42 \%$ of the patients improved back to wellnourished as they recovered from the side effects of the treatment.

The majority of HNC patients were at an advanced stage and were found to have a high tendency for nutritional depletion with inadequate energy and protein intake. The average daily energy and protein intake in this study were below the ESPEN recommended guideline of 25-30 kcal/ $\mathrm{kcal}$ of body weight and 1.2-1.6 g/ kg/body weight at baseline of treatment [15]. An improvement of average daily energy and protein intake was found at the end and after the treatment compared to the baseline (Table 2), however, the intake was still below the ESPEN recommendation, respectively. The patients in this study who started to lose weight continued to lose it throughout the treatment as a consequence of inadequate energy and protein intake. As the treatment was completed, the average of calories and protein intake increased, as compared to the baseline intake which is similar to another study [16]. It was expected that significant weight loss is due to eating problems. Some studies have shown a relation of insufficient knowledge of food and nutrition among cancer patients, which has an impact on nutritional outcomes [17]. Some studies have shown that the majority of cancer patients who have dietary perceptions and beliefs with specific food restrictions, result in a high risk of malnutrition after diagnosis [18,19].

Most HNC patients were required to change their type of diet during treatment which was similar to $[5,16]$ where some HNC patients could not eat and needed to adjust their food intake or rely on nutritional support to get sufficient energy and protein intake (Figure 1). As patients suffer multiple NIS in the middle and at the end of treatment, nearly $50 \%$ of patients chose a liquid diet rather than a normal diet. For those who are suffering from the symptom of a dry mouth, foods that were cold, moist, softly textured, and came with sauces, broths or soupy foods were preferred. In the study, dry foods and spices were required to be excluded due to a sore mouth or throat, which showed that a normal diet was not tolerated among HNC patients after treatment. Many HNC patients had struggled to eat sufficiently as they lost the pleasure in food and eating due to changes in taste and limited food choices [20].

The majority of HNC patients in this study required ONS, which is almost similar to Hopanci et al.'s (2017) [21] study in which 95\% of the HNC patients were prescribed ONS during RT as it was shown that during treatment, fat mass and fat-free mass remain unchanged (Table 3). In this study, about $70 \%$ of total energy and protein intake were contributed to ONS in the middle and end of treatment with the majority of patients having shown a high score of NIS that interrupted their dietary intake and lead to weight loss.

The NIS score and ONS energy and protein intake showed an increasing trend during treatment. The majority of patients continued to have eating problems and causes of eating problems such as pain, chewing and swallowing difficulties, loss of appetite, dry mouth, taste changes, sore mouth, and thick saliva required ONS to increase their energy and protein intake. While in the post-treatment, as it is a rehabilitation phase, the persistence of NIS is reduced meaning oral intake should have improved, which led to less total energy and protein from ONS. 
All HNC patients had multiple NIS at the end of treatment, resulting in a high NIS score (Table 4), which was comparable with Kubrak et al.'s (2013) study [22]. All of these NIS were interrelated with each other in that they interfered with dietary intake. Dry mouth exposes a higher risk of oral mucositis due to the breakdown of the mucosal barrier that promotes bacterial growth with high levels of pro-inflammatory cytokines, which may cause anorexia problems. Multiple NIS are associated with malnutrition risk, weight loss, dietary intake and quality of life. The majority of patients in the present study continued to have taste changes, chewing difficulties, mouth dryness and thick saliva after completion of the treatment. These NIS were the most common side effects after 1 and 6 months.

The NIS data and malnutrition status in this study allow us to design a more effective nutrition intervention and monitor the patients' condition in the future. This is the first study to evaluate the post-treatment RT among HNC patients. It is crucial to generate comprehensive data of the post-treatment RT assessment in order to identify early symptoms, prevent severe weight loss and improve treatment outcomes by providing an effective nutritional intervention among HNC patients. This may highlight the need for continuous assessment of malnutrition status, dietary changes, and NIS to provide comprehensive nutritional intervention and monitoring after completion of treatment. A limitation of this study should be noted. The generalization of these results among HNC patients may not be allowed as the sample size is small. Nevertheless, the result of this study serves as a reference and benchmark for further research on weight changes and other nutrition parameters in HNC during and after post-treatment RT, to ensure the optimization of nutritional intervention.

\section{Conclusions}

Overall, HNC patients in this study experienced weight loss, a decline of energy and protein intake, and NIS scores at the end of treatment but all of these parameters were improved during post-treatment. The post-treatment recovery stage is also very important for HNC patients as eating problems still remain a common issue and food intake adjustment is required from time to time to ensure a healing process. Continuous follow-up is therefore important to monitor the progression of complications and for the maintenance of nutritional status.

Author Contributions: Conceptualization, methodology, investigation, resources, data curation, formal analysis, visualization and writing original drafts, M.K.N. and Z.A.Z.; supervision, Z.A.Z., Z.A.M.D., N.B.M.Y. and Z.I.; writing—review and editing, Z.A.Z., Z.A.M.D., N.B.M.Y., Z.I., N.J., Z.A.R. and A.Z.A.A.; project administration, M.K.N., Z.A.R. and N.J. All authors have read and agreed to the published version of the manuscript.

Funding: This research received no external funding.

Institutional Review Board Statement: The study was registered in the National Medical Research Registry Malaysia (NMRR ID 17-2647-37667). The ethical approval was approved by the Medical Research Ethics Committee of the Faculty of Medicine and Health Sciences, Universiti Putra Malaysia and the Medical Research Ethics Committee (MREC), Ministry of Health Malaysia.

Informed Consent Statement: Informed consent was obtained from all subjects involved in the study.

Data Availability Statement: Data are available upon request.

Acknowledgments: The authors would like to express their sincere appreciation to the General Director of the Ministry of Health, Malaysia, for approval of this study as well as the Department of Administration, National Cancer Institute, Putrajaya, for their assistance in this study. Moreover, we thank the patients who participated and contributed to this study.

Conflicts of Interest: The authors declare no conflict of interest. 


\section{References}

1. Stewart, B.W.; Wild, C.P. World Cancer Report 2014; World Health Organization: Geneva, Switzerland, $2014 ;$ pp. 1-2.

2. Ferlay, J.; Colombet, M.; Soerjomataram, I.; Mathers, C.; Parkin, D.M.; Piñeros, M.; Znaor, A.; Bray, F. Estimating the global cancer incidence and mortality in 2018: GLOBOCAN sources and methods. Int. J. Cancer 2019, 144, 1941-1953. [CrossRef] [PubMed]

3. Bressan, V.; Stevanin, S.; Bianchi, M.; Aleo, G.; Bagnasco, A.; Sasso, L. The effects of swallowing disorders, dysgeusia, oral mucositis and xerotomia on nutritional status, oral intake and weight loss in head and neck cancer patients: A systematic review. Cancer Treat. Rev. 2016, 45, 105-119. [CrossRef] [PubMed]

4. Dechaphunkul, T.; Martin, L.; Alberda, C.; Olson, K.; Baracos, V.; Gramlich, L. Malnutrition assessment in patients with cancers of the head and neck: A call of action and consensus. Crit. Rev. Oncol. Hematol. 2013, 88, 459-476. [CrossRef] [PubMed]

5. Ottosson, S.; Zackrisson, B.; Kjellén, E.; Nilsson, P.; Laurell, G. Weight loss in patients with head and neck cancer during and after conventional and accelerated radiotherapy. Acta Oncol. 2013, 52, 711-718. [CrossRef] [PubMed]

6. Ghadjar, P.; Hayoz, S.; Zimmermann, F.; Bodis, S.; Kaul, D.; Badakhshi, H.; Bernier, J.; Studer, G.; Plasswilm, L.; Budach, V.; et al. Impact of weight loss on survival after chemoradiation for locally advanced head and neck cancer: Secondary results of a randomized phase III trial (SAKK 10/94). Radiat. Oncol. 2015, 10, 21-27. [CrossRef] [PubMed]

7. $\quad$ Langius, J.A.E.; Twisk, J.; Kampman, M.; Doornaert, P.; Kramer, M.H.H.; Weijs, P.J.M.; Leemans, C.R. Prediction model to predict critical weight loss in patients with head and neck cancer during (chemo)radiotherapy. Oral Oncol. 2016, 52, 91-96. [CrossRef] [PubMed]

8. Nourissat, A.; Bairati, I.; Fortin, A.; Gelinas, M.; Nabid, A.; Brochet, F.; Tetu, B.; Meyer, F. Factors associated with weight loss during radiotherapy in patients with stage I or II head and neck cancer. Supportive Care Cancer 2012, 20, 591-599. [CrossRef] [PubMed]

9. Bossola, M. Nutritional interventions in head and neck cancer patients undergoing chemoradiotherapy: A narrative review Nutrients 2015, 7, 265-276. [CrossRef]

10. Farhangfar, A.; Makarewicz, M.; Ghosh, S.; Jha, N.; Scrimger, R.; Gramlich, L.; Baracos, V. Nutrition impact symptoms in a population cohort of head and neck cancer patients: Multivariate regression analysis of symptoms on oral intake, weight loss and survival. Oral Oncol. 2014, 50, 877-883. [CrossRef] [PubMed]

11. Lee, S.C.; Wang, T.J.; Chu, P.Y. Predictors of weight loss during and after radiotherapy in patients with head and neck cancer: A longitudinal study. Eur. J. Oncol. Nurs. 2019, 39, 98-104. [CrossRef] [PubMed]

12. May, K.N.; Zalina, A.B.; Zulfitri, A.M.D.; Nor, B.M.Y.; Zuriati, I.; Zuwariah, A.B.; Norshariza, J. Changes in nutrition impact symptoms, nutritional and functional status during head and neck cancer treatment. Nutrients 2020, 12, 1225. [CrossRef]

13. Ackermen, D.; Laszlo, M.; Provisor, A.; Yu, A. Nutrition Management for the Head and Neck Cancer Patient. In Multidisciplinary Care of the Head and Neck Cancer Patient; Springer: Cham, Switzerland, 2018; Volume 174, pp. 187-208.

14. Wei, J.; Wu, J.; Meng, L.; Zhu, B.; Wang, H.; Xin, Y.; Chen, Y.; Cui, S.; Dong, L.; Jiang, X. Effects of early nutritional intervention on oral mucositis in patients with radiotherapy for head and neck cancer. QJM 2020, 113, 37-42. [CrossRef] [PubMed]

15. Muscaritoli, M.; Arends, J.; Bachmann, P.; Baracos, V.; Barthelemy, N.; Bertz, H.; Bozzetti, F.; Hutterer, E.; Isenring, E.; Kaasa, S.; et al. ESPEN practical guideline: Clinical Nutrition in Cancer. Clin. Nutr. 2021, 40, 2898-2913. [CrossRef] [PubMed]

16. Nejatinamini, S.; Kubrak, C.; Álvarez-Camacho, M.; Baracos, V.E.; Ghosh, S.; Wismer, W.V.; Mazurak, V.C. Head and neck cancer patients do not meet recommended intakes of micronutrients without consuming fortified products. Nutr. Cancer 2018, 70, 474-482. [CrossRef] [PubMed]

17. Srivastava, R.; Gupta, V.G.; Dhawan, D.; Geeta, K.; Bakhshi, S. Poor nutritional knowledge and food restrictions among families of children with cancer and their impact: A cross-sectional study of 700 families. J. Psychosoc. Oncol. 2018, 36, 658-666. [CrossRef] [PubMed]

18. Totadri, S.; Radhakrishnan, V.; Atreya, H.; Shenoy, P.K.; Ganesan, P.; Ganesan, T.S.; Sagar, T.G. Dietary perceptions and beliefs among families with children undergoing therapy for cancer. Pediatr. Hematol. Oncol. J. 2017, 2, 25-28. [CrossRef]

19. Beeken, R.J.; Williams, K.; Wardle, J.; Croker, H. "What about diet?" A qualitative study of cancer survivors' views on diet and cancer and their sources of information. Eur. J. Cancer Care 2016, 25, 774-783. [CrossRef] [PubMed]

20. Ottoson, S.; Laurell, G.; Olsson, C. The experience of food, eating, and meals following radiotherapy for head and neck cancer: A qualitative study. J. Clin. Nurs. 2013, 22, 1034-1043. [CrossRef] [PubMed]

21. Hopanci, B.D.; Ozkaya, A.O.; Meseri, D.R.; Esassolak, M.; Uslu, R.; Uyar, M. The Effects of Compliance with Nutritional Counselling on Body Composition Parameters in Head and Neck Cancer Patients under Radiotherapy. J. Nutr. Metab. 2017, 2017, 8631945. [CrossRef] [PubMed]

22. Kubrak, C.; Olson, K.; Baracos, V.E. The head and neck symptom checklist@: An instrument to evaluate nutrition impact symptoms effect on energy intake and weight loss. Supportive Care Cancer 2013, 21, 3127-3136. [CrossRef] [PubMed] 